\title{
Molecular detection of cryptic Y-chromosomal material in patients with Turner syndrome
}

\author{
ELVA I. CORTÉS-GUTIÉRREZ ${ }^{1}$, ROSALBA HERRERA-BARTOLO ${ }^{2}$, MARTHA I. DÁVILA-RODRÍGUEZ ${ }^{1}$, \\ GERARDO C. PALACIOS-SAUCEDO ${ }^{2}$, JAVIER VARGAS-VILLARREAL ${ }^{3}$ and JUANA B. ROMERO-VILLARREAL ${ }^{2}$ \\ ${ }^{1}$ Department of Genetics, Biomedical Research Center of Northeast (CIBIN), Mexican Institute of Social Security (IMSS); \\ ${ }^{2}$ Deparment of Pediatrics, High Specialty Medical Unit No. 25, IMSS; ${ }^{3}$ Department of Cellular and \\ Molecular Biology, CIBIN, IMSS, Monterrey, Nuevo León, Mexico
}

Received October 7, 2011; Accepted November 28, 2011

DOI: $10.3892 /$ or.2012.1916

\begin{abstract}
A systematic search for a hidden Y-chromosome mosaicism, in Turner syndrome (TS) patients is justified by the evaluation of the risk of development of germ cell tumors. In this study, we analyzed cryptic Y-chromosome derivatives by polymerase chain reaction (PCR) coupled with fluorescence in situ hybridization (FISH) using Y-specific sequences in patients with TS, and validated this methodology. Unrelated patients with TS $(n=32)$ of Mexican mestizo ethnic origin were diagnosed using cytogenetic analysis. Clinical assessment, endocrine evaluation, karyotyping, FISH and PCR analysis of the Y-chromosomal loci were performed. We found that $9.4 \%$ (3 out of 32) patients with TS had Y-chromosome material. Two patients showed Y-chromosome by conventional cytogenetics. One patient had no Y-chromosome by initial karyotyping $(45, \mathrm{X})$ but was positive by lymphocyte PCR DNA analysis of the Y-sequence-specific sex-determining region Y (SRY) gene. Our results suggest that the detection of the Y-chromosome material using sensitive methods, such as PCR coupled with FISH, should be carried out in all patients with TS and should not be limited to TS patients with cytogenetically identifiable Y-chromosome and/or virilization.
\end{abstract}

\section{Introduction}

Turner syndrome (TS) is one of the most common human chromosomal abnormalities occurring in approximately 1:2,500 live female births. It is characterized by short stature, gonadal dysgenesis, typical visible dysmorphic stigmata, and urinary, cardiovascular, and skeletal abnormalities $(1,2)$. This syndrome has been associated with a wide range of

Correspondence to: Dr Elva I. Cortés-Gutiérrez, Department of Genetics, Biomedical Research Center of Northeast (CIBIN), Mexican Institute of Social Security (IMSS), Monterrey, Nuevo León, Mexico

E-mail: elvacortes@cibinmty.net

Key words: Turner syndrome, chromosome Y, sex-determining region Y gene, gonadal dysgenesis chromosomal karyotypes. The most frequent is $45, \mathrm{X}$ monosomy, however, a variety of other anomalies have been found, including mosaicism, $\mathrm{Xp}$ or $\mathrm{Xq}$ deletion, and isochromosome of the long arm of chromosome $X$ (2). In addition, a cell line with a Y-chromosome is present in $5 \%$ of patients, and an additional $3 \%$ of cases have an unidentifiable marker sex chromosome, presumably derived from a Y-chromosome in pure or mosaic form (3). It has been proposed that all female patients with TS and 45, X karyotypes carry a cell line containing 2 sex chromosomes at a low level of mosaicism (4), which is undetectable using standard cytogenetics analysis. Theoretically, this hidden mosaicism may have a Y-chromosome. The gonadal dysgenesis seen in patients with TS is associated with gonadoblastoma in cases where the Y-chromosome-derived material is present in the genome (5).

The presence or absence of the Y-encoded male-determining sex-determining region $\mathrm{Y}$ (SRY) gene directs the developing gonad to differentiate into either a testis or an ovary, which in turn determines the sex development of the remainder of the embryo (6). The SRY gene increases the risk of developing gonadoblastoma and/or non-tumoral gonadal lesions in TS. It may be useful to perform molecular analyses in these subjects, to rule out the presence of Y-chromosome sequences $(7,8)$.

The expression analysis of genes SRY, octamer-binding transcription factor 4 (OCT4), and testis-specific protein $\mathrm{Y}$ encoded gene (TSPY) in TS patients with gonadal dysgenesis may allow introducing modifications in the microenviroment that could contributed to a malignant transformation (9).

A systematic search for hidden Y-chromosome mosaicism, especially SRY, in TS patients is justified by the possibility of evaluating the risk of development of germ cell tumor (10-13).

In this report, the aims of the study were to use PCR coupled with FISH, to determine the presence, and incidence of cryptic Y-chromosome material in patients with TS.

\section{Materials and methods}

Population under study. Thirty-two unrelated TS patients of Mexican mestizo ethnic origin aged 9.9 \pm 3.4 years (mean \pm SD; range, 4-15 years) that were examined at the Department of Endocrinology, High Specialty Medical Unit No. 25 (UMAE), 
Mexican Institute of Social Security (IMSS) in Monterrey, Mexico, between 2005 and 2009 were enrolled in this study. The clinical diagnosis of the patients was set upon the medical history and presented clinical features at 1 of 3 major stages of maturation, namely at birth, when typical signs of TS appeared (congenital lymphedema: puffy hands and feet or redundant nuchal skin), at mid-childhood, when TS appeared as growth retardation with or without TS phenotypic finding, and in adolescence, when they failed to enter puberty (primary amenorrhea). The exclusion criteria were: ambiguous genitalia or enlargement of the clitoris.

The diagnosis of TS was verified by cytogenetic analysis (standard karyotyping) in all cases.

The Ethics Committee of the UMAE No. 25, IMSS, approved the study. The parents provided informed consent for the participation of their daughters in this study.

All women were evaluated by gynecologists via a physical examination, sonogram of the pelvis, and an endocrinological test. The samples were sent to the Cytogenetic-Molecular Laboratory of the Biomedical Research Center of Northeast (CIBIN), IMSS, for chromosomal and molecular studies.

Cytogenetic analysis. Karyotyping was performed from blood lymphocyte cultures using G-banding by trypsin/Giemsa (GTG) analysis (14). Thirty cells were counted per patient (this was increased to 100 in cases of mosaicism).

Fluorescence in situ hybridization (FISH). FISH was performed according to the manufacturer's protocol (VYSIS, Inc., Downers Grove, IL, USA) on lymphocytes using a CEP-Y (Spectrum Orange) probe, which hybridizes to the centromere region of the Y-chromosome (Yp11.1-q11.1). FISH analysis was also performed on gonadal tissues from the 3 patients who underwent gonadectomy.

The slides were viewed under a Zeiss Axiophot photomicroscope equipped with an epifluorescence system and a CCD camera. All samples were analyzed in duplicate, in a blinded manner. Five hundred interphase nuclei, and 30 metaphases were analyzed per patient.

Molecular genetic analysis. Peripheral blood samples were collected from 32 TS patients. DNA was isolated using a DNA isolation kit for mammalian blood (Roche Diagnostics, Mannheim, Germany). In 3 patients which underwent gonadectomy, DNA was also extracted from paraffin-embedded gonadal tissues using the QIAmp Tissue kit (Qiagen Inc., Hilden, Germany).

The SRY gene, which is located in the short arm of the Y-chromosome (Yp11.3), was used for the detection of cryptic chromosome material using PCR analysis. PCR reactions were performed in a volume of $25 \mu \mathrm{l}$, which contained extracted DNA, primers (20 pmol; SRY1, 5'-ATAAGTATCGACCTCGTCGGAAG-3'; and SRY2, 3'-GCACTTCGCTGCAGAGTACCGAAG-3'), DNA polymerase (2.5 units), 1X PCR buffer containing $1.5 \mathrm{mM} \mathrm{MgCl}_{2}$, and $200 \mu \mathrm{M}$ of each dNTP. Thermal cycling was performed as follows: initial activation of TaqDNA polymerase at $94^{\circ} \mathrm{C}$ for $5 \mathrm{~min}$, followed by 30 cycles of denaturation at $94^{\circ} \mathrm{C}$ for $30 \mathrm{sec}$ and annealing at $56^{\circ} \mathrm{C}$ for $30 \mathrm{sec}$. A final extension at $72^{\circ} \mathrm{C}$ for $5 \mathrm{~min}$ was performed. The PCR amplification products were separated
Table I. Distribution of karyotypes among 30 Mexican patients with Turner syndrome.

\begin{tabular}{|c|c|}
\hline Karyotype & $\mathrm{N}(\%)$ \\
\hline $45, X$ & $24(75)$ \\
\hline $45, \mathrm{X} / 46, \mathrm{XX}$ & $4(12.5)$ \\
\hline $45, X / 46, X, \operatorname{del}(X q)$ & $1 \quad(3.1)$ \\
\hline 46, Xi (Xq) & 1 (3.1) \\
\hline $45, \mathrm{X} / 46, \mathrm{X}, \mathrm{mar}$ & $1(3.1)$ \\
\hline $45, \mathrm{X} / 46, \mathrm{XY}$ & 1 (3.1) \\
\hline Total & $32(100)$ \\
\hline
\end{tabular}
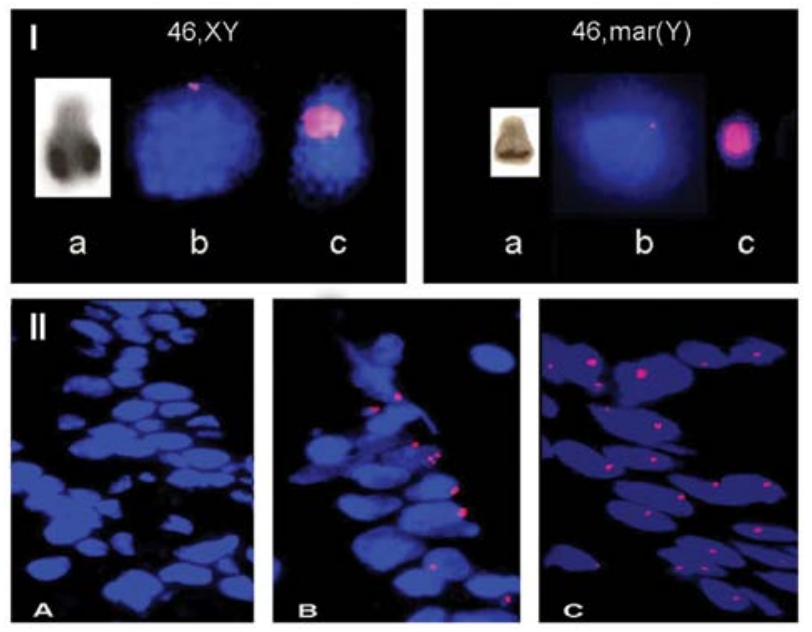

Figure 1. (I) G-bands of Y-chromosome (a), fluorescence in situ hybridization (FISH) in lymphocytes (b) and chromosomes (c) using the CEP-Y probe, which hybridizes to the centromere region of the Y-chromosome in case 2 $(46, \mathrm{XY})$ and case 1 [(46, mar (Y)]. (II) (B) Interphase FISH in biopsy tissue samples of case 3, (A) genital skin of a female (used as a negative control), and (C) genital skin of a male (used as a positive control), using the CEP-Y probe.

using 2\% agarose gel electrophoresis and were visualized by exposure to ultraviolet light after ethidium bromide staining.

For the FISH and molecular analysis, 5 healthy females and 5 healthy males were included as negative and positive control groups, respectively. All DNA extractions and PCR reactions were performed by a female technician, to avoid the risk of contamination with male DNA.

\section{Results}

Clinical. The referral data revealed that short stature (100\%) and the presence of streak-like or invisible gonads $(28.1 \%)$ on ultrasonography were the most common findings. Additionally, 6 patients $(18.7 \%)$ had cardiac anomalies and 2 patients $(6.2 \%)$ had renal anomalies (renal agenesis or ectopic kidneys). All patients had clinical features of TS and did not show signs of virilization.

The hormonal profiles were as follows: $\mathrm{LH}=9.3 \mathrm{UI} / 1$ (range, 0.74-28.9), FSH=66.2 UI/1 (range, 1.64-172.41), and $\mathrm{TSH}=2.26 \pm 0.59 \mathrm{UI} / 1$ (range, 0.55-3.43).

Cytogenetics (G-banding). The cytogenetic findings of the cases analyzed in the present study are summarized in Table I. 
Table II. Results of karyotyping (GTG), FISH, PCR-SRY, and surgical reports of Turner patients with Y-chromosome positive.

\begin{tabular}{llll}
\hline & \multicolumn{1}{c}{ Case 1} & \multicolumn{1}{c}{ Case 2} & Case 3 \\
\hline Age (years) & 7 & 10 & 13 \\
Karyotype (GTG) & $45, \mathrm{X} / 46$, mar & $45, \mathrm{X} / 46, \mathrm{XY}$ & $45, \mathrm{X}$ \\
FISH (lymphocytes) & $45, \mathrm{X} / 46, \mathrm{mar}(\mathrm{Y})(57 / 43)$ & $45, \mathrm{X} / 46, \mathrm{XY}(62 / 38)$ & $45, \mathrm{X}$ \\
FISH (gonads) & cepY-[43]/cepY+[57] & cepY-[54]/cepY+[46] & cepY-[74]/cepY+[26] \\
PCR-SRY (lymphocytes) & Positive & Positive & Positive \\
PCR-SRY(gonads) & Positive & Positive & Positive \\
Histology & Streak gonads & Gonodoblastoma & Streak gonads \\
\hline
\end{tabular}
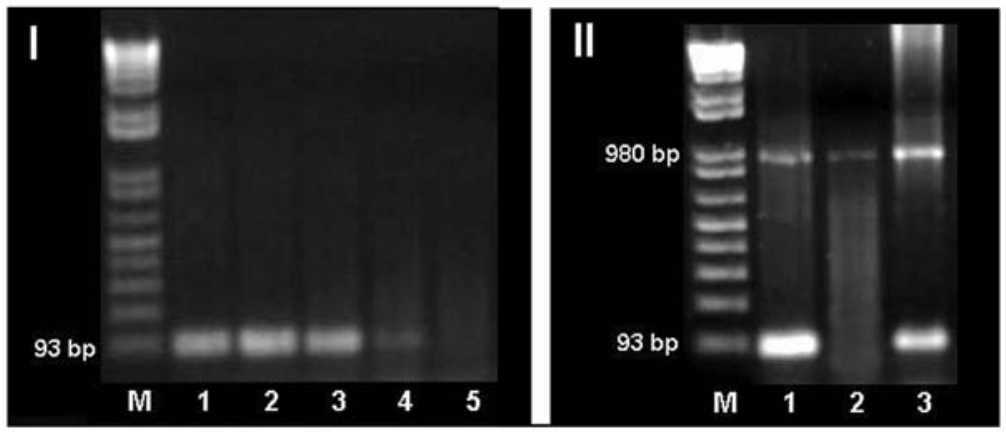

Figure 2. (I) PCR detection of SRY in serial dilution of male genomic DNA with female genomic. M, molecular weight marker; lane 1, SRY male control; lanes 2-5 correspond to dilutions 1:10, 1:100, 1:1,000 and 1:2,000 respectively. (II) PCR detection of SRY. M, molecular weight marker; lane 1, SRY male control; lane 2, SRY female control and lane 3, case 3.

As shown, most of the TS cases had a 45, X karyotype, $75 \%$ with a pure line and $25 \%$ with mosaicism; 4 cases had a $46, \mathrm{XX}$ karyotype, 2 patients had Y-chromosome [45, X/46, X,mar (case 1) and 45, X/46, XY (case 2)], 1 case had an Xq deletion. One patient $(3.1 \%)$ presented isochromosome $\mathrm{Xq}$ in pure form.

FISH analysis. Using a specific probe for the Y-chromosome, signals of appreciable intensity were detected in lymphocytes from male controls, whereas no signals were observed in cells obtained from female controls.

FISH analysis in lymphocytes confirmed Y-chromosome positivity in case 2, and the marker chromosome was shown to be of Y-chromosome origin (case 1) (Fig. 1I). No Y-chromosome was detected in case 3 (Table II). FISH analysis on gonadal tissues revealed that Y-chromosome material was present in 57,46 and $26 \%$ of cells, respectively (Table II, and Fig. 1IIB).

PCR of the SRY gene. PCR of the SRY gene was performed using DNA obtained from peripheral blood cells and gonadal tissues. An internal control was used to confirm the presence and availability of DNA in the sample; this control consisted of a region of the glyceraldehyde-phosphate dehydrogenase (GADPH) gene for peripheral blood and $\beta$-globin gene for gonadal tissues, which were amplified simultaneously, yielding a PCR product of 980 and $260 \mathrm{bp}$ respectively. The $\beta$-globin gene was used in gonadal tissues because the DNA extracted by QIAmp Tissue kit did not amplify a PCR product of $980 \mathrm{pb}$. All samples showed amplification bands of the expected size.

To determine the sensitivity of the SRY gene PCR, a serial dilution of male genomic DNA with female genomic DNA was used as a template. We were able to detect Y-specific products up to 1:1,000 dilution of male positive control DNA with female DNA. This method is capable of detecting Y-chromosome fragments in the samples, if at least $0.1 \%$ of the cells contained Y-chromosome material (Fig. 2I).

PCR of the SRY gene, as expected, generated a band of 93 bp when male genomic DNA was used as a template; in contrast, no amplification products were detected when female genomic DNA was used as a template.

PCR of SRY was performed on genomic DNA obtained from blood cells of all 32 patients. We confirmed the presence of the Y-chromosome in cases 1 and 2, and detected 1 patient (case 3) with a Y-chromosome, who was initially considered as Y-negative (Table II and Fig. 2II).

PCR-SRY gonadal analysis was positive in all 3 cases. The prophylactic operation reveled than 1 of the cases (case 2) had bilateral gonadoblastoma without any clinical signs (Table II).

\section{Discussion}

Standard karyotyping is a routinely applied method for testing Y-chromosome positivity in TS. However, this frequently applied method may miss cases if the Y-chromosome is present only in a small proportion of cells or very small parts of the Y-chromosome or even marker chromosomes containing Y-specific regions are present (15).

FISH highlights the differences between the initial diagnosis based on G-banding, and final diagnoses, determined by specific probes for the $\mathrm{X}$ and Y-chromosome. FISH (using a large number of cells) is a useful tool in the detection of 
Table III. Prevalence of cryptic Y-chromosomal material in patients with TS in previous studies.

\begin{tabular}{cccc}
\hline Reference & Methods & $\begin{array}{c}\text { Cryptic Y-chromosomal } \\
\text { material }(\%)\end{array}$ & Conclusion
\end{tabular}

$\begin{array}{rlr}\text { Gravholt } \text { et al (5) } 114 & \begin{array}{l}\text { PCR: ZFY, SRY, DYZ3, } \\ \text { DY132 and DYZ1 }\end{array}\end{array}$

Binder et al (18)

53 Nested PCR: SRY, TSP, Y-encoded, DYZ3

Coto et al (19)

18 PCR: SRY, DYZ3

Fernández et al (20)

41 FISH: CEP-X, CEP-Y, WCP-X WCP-Y, XIST, DXZ4, SCPL 116, SCPL102. PCR: SRY

Álvarez-Nava et al (28) 52 FISH: CEP-X, CEP-Y, WCP-X WCP-Y, PCR: PABY, SRY, ZFY, DYS19, DYZ3. Amelogenin, Kal-Y, DYZ1, TSPY, YRRM

Larsen et al (30)

Mendes et al (31)

40 FISH: SRY, ZFY, DYZ3, DYZ1 and DYS132 PCR: microsatellite

36 PCR: SRY, ZFY, DYZ3

Nishi et al (32)

122 Nested PCR: SRY, TSPY

Canto et al (33)

107 PCR: SRY, ZFY, Yc and Yq

López et al (23)

Sallai et al (16)

Semerci et al (35)

Bianco et al (11)

Araujo et al (36)

Kim et al (37)
20 PCR: SRY, DYZ3

42 PCR: SRY, DYZ3, ZFY, DYZ1, DYS1 and PABY

50 Southern blotting: ZFY, SRY, Yqh, Ycen. PCR: ZFY, SRY, Yqh, Ycen

130 FISH: SRY, DEAD/H box polypeptide, DDX3Y, HSFY1, TSPY1. RT-PCR

40 PCR: PABY, SRY, DYS14, AMGY, DYZ3, DYS273, DYS280, DYS218, DYS224, DYS209, DYS231, DYS1, YRRM, DYZ1
61.1

Future studies should be undertaken to focus on the incidence of gonadoblastoma in the presence of Y-chromosome material in all diagnosed females with Turner syndrome. This study emphasizes the need for prospective unbiased studies.

The data in this study exclude low level Y-mosaicism in almost all TS cases tested.

Sensitive method for the detection of Y as PCR has important implications for UTS patients to evaluate the risk of gonadoblastoma.

This study support the hypothesis of "the necessity of mosaicism for survival', and thus, a mitotic origin for this syndrome.

Detection of the Y-chromosome material should be carried out in all patients with TS.

Contrary to other reports using the PCR technique to unravel 'hidden' Y-chromosome mosaics, we did not find any positive cases.

The molecular study was sensitive and useful in the evaluation of patients at risk of developing gonadoblastoma.

Nested PCR overestimated the frequency of Y-sequences in patients with TS.

Because of the high proportion of gonadal tumors in patients with Y-chromosome sequences, adequate counseling regarding a gonadectomy should be given.

This study discusses the presence of Y-sequences in patients with UTS and compares the frequency with that previously reported.

A routine molecular screening for hidden Y-chromosome sequences in TS is recommended in order to calculate the risk of developing gonadoblastoma.

The patients with a 45, X karyotype should be analyzed for the presence of Y-chromosome derivatives by sensitive methods, such as PCR, in order to calculate the future risk of developing gonadoblastoma.

A systematic search for hidden Y-chromosome mosaicism in patients with TS and 45, $\mathrm{X}$ karyotype is justified by the possibility of developing gonadoblastoma.

PCR method should be included in the routine assistance of TS patients.
It may be reasonable to consider using a PCR method to screen for Y-specific sequences in all patients with TS. 
low frequency cell lines and identification of the nature and origin of derivative chromosomes and unknown chromosome markers that have important implications for the treatment of patients with TS (15).

Recombinant DNA technology has enabled the analysis of sex chromosome abnormalities at the molecular level in patients with TS. In addition, it has helped the identification of the parental origin of the abnormality, the existence of cytogenetically hidden mosaicism, and the correlation between genotypes and phenotypes. Molecular analytical techniques as PCR are useful in complementing the genetic approach used in TS $(16,17)$. This analysis has advantages over the cytogenetic analysis, as it is rapid and several samples can be analyzed in parallel; it could be applied to the broader screening of a larger number of patients, and to the achievement of greater sensitivity in the recognition of mosaicism (18-26).

On the basis of clinical experience, it is generally accepted that mixed gonadal dysgenesis increases the risk for germ cell tumor when Y-chromosome is present. Recently, the importance of detecting the presence of the Y-chromosome and significance of the ratio of mosaicism in gonadal tissues have been raised (11-13,27).

Previous studies in TS patients with different karyotypes have demonstrated the presence of Y-chromosome-derived sequences (0-61\%), and emphasize the clinical necessity of molecular analysis of hidden Y-mosaicism in TS for the evaluated risk of developing gonadoblastoma (Table III). This variability may be caused by molecular methods used, selection criteria of the patients, racial variation, different tissues examined, and the selection of the Y-chromosome-specific primers $(5,18-20,23,26,28-33)$.

We found that $9.4 \%$ (3 out of 32) Mexican patients with TS had Y-chromosome material; 2 patients showed Y-chromosome by conventional cytogenetic analysis, and 1 patient had no Y-chromosome on initial karyotype analysis $(45, \mathrm{X})$ but was positive when lymphocyte DNA was analyzed by Y-sequence-specific gene analysis.

Page (34) suggested that FISH or PCR analysis should be performed only in patients with clitoromegaly, signs of virilization, and those that show marker chromosomes using conventional analysis. In contrast, using PCR, we identified 1 patient $(3.1 \%)$ that was a carrier of cryptic Y-chromosome material with neither virilization nor marker chromosome positivity. Other authors have demonstrated that Venezuelan patients with a 45, X karyotype had cryptic Y-specific sequences $(3.8 \%)$ (28); similar results were reported in Turkish patients (5\%) (35), in Brazilian patients (4.8\%) (36), in Hungarian patients $(4.7 \%)(16)$, and in Korean patients $(3.2 \%)$ (37).

The results of our study favor the idea that all patients with TS should be assessed using DNA analysis. In our study, 1 patient with a 45, X karyotype had hidden Y-chromosome material that was detectable by DNA analysis in blood cells. FISH analysis in gonadal tissue revelead than Y-chromosome material was present in $26 \%$ of cells. She was 13 -years-old, had no virilization, and no gonadoblastoma was found on the gonads.

Similar findings have been reported by other researchers $(29,38)$. These studies have documented the presence of Y-chromosomes on gonadal fibroblasts, but not on leukocytes.
This could be due to erratic behavior during the mitosis of this abnormal Y-chromosome, which may lead to an uneven distribution of cells bearing the Y-chromosome.

It has been shown that the detection of chromosomal mosaicism can be enhanced substantially if at least 2 kinds of tissue and a large number of cells are examined (39). It is easier and more practical to test chromosomal mosaicism using 2 methods (karyotype, FISH, or PCR analyses) compared with the testing of 2 tissues (e.g., peripheral blood, oral epithelial cells, hair root, skin, and muscle). Thus, we suggest that all patients with TS should be screened using chromosomal analysis of blood cells and PCR analysis, to rule out the possibility of hidden Y-chromosome mosaicism in cases where the karyotype did not identify Y-chromosome material.

The more expensive and time consuming FISH technique is helpful to evaluate Y-chromosome rearrangements, but, on the basis of our results, we suggest it is use only after a positive PCR results.

In the present study, using PCR coupled with FISH, the analysis was more sensitive and method for the assessment of hidden Y-chromosome mosaicism in patients with TS with or without an a priori risk (i.e., presence of a Y-chromosome that is identifiable cytogenetically) of development of gonadoblastoma or neonatal or postpuberal virilization.

From an ethical point of view, it is impossible to establish a prospective study to directly measure gonadoblastoma incidence in humans, as prophylactic gonadectomy is the common procedure in cases of Y-chromosome material carriers (40). In our study, the prophylactic operation was carried out in all 3 patients, and 1 (3.1\%) of them had bilateral gonadoblastoma without any clinical signs. This prevalence is in agreement to previous studies $(8,33)$.

In further studies we recommend the use of primers than analyze a wider region of the SRY gene than includes the HMG (high mobility group) box, and other genes, such as TSPY1, which have recently been identified as gonadoblastoma candidate genes and will be tested $(40,41)$.

In conclusion, our data support the suggestion that these patients be analyzed for the presence of Y-chromosome derivatives using sensitive methods, such as PCR coupled with FISH, to predict the future risk of development of gonadoblastoma. However larger studies are needed to determine the most appropriate clinical management of these patients.

\section{Acknowledgements}

The authors are grateful to the Department of Pediatrics of UMAE No. 25, IMSS for the use of facilities to sample and interview participants in the study. We are grateful to Sanjuana Guardado Limón for excellent technical assistance.

\section{References}

1. Ranke MB and Saenger P: Turner's syndrome. Lancet 358: 309-314, 2001.

2. Saenger P, Wikland KA, Conway GS, et al: Recommendations for the diagnosis and management of Turner syndrome. J Clin Endocrinol Metab 86: 3061-3069, 2001.

3. Nagafuchi S, Tamura T, Nakahori Y, et al: The majority of the marker chromosomes in Japanase patients with stigmata of Turner syndrome are derived from Y chromosome. Hum Genet 89: $590-592,1992$ 
4. Held KR, Kerber S, Kaminsky E, et al: Mosaicism in 45, X Turner syndrome: does survival in early pregnancy depend on the presence of two sex chromosomes? Hum Genet 88: 288-294, 1992.

5. Gravholt CH, Fedder J, Naeraa RW and Müller J: Occurence of gonadoblastoma in females with Turner syndrome and Y chromosome material: a population study. J Clin Endocrinol Metab 85: 3199-3202, 2000.

6. Sekido R: SRY A transcriptional activator of mammalian testis determination. Int J Biochem Cell Biol 42: 417-420, 2010

7. Chu CE, Connor JM, Donaldson MD, Kelnar CJ, Smail PJ and Greene SA: Detection of Y mosaicism in patients with Turner's syndrome. J Med Genet 32: 578-580, 1995.

8. Mazzanti L, Cicognani A, Baldazzi L, et al: Gonadoblastoma in Turner syndrome and Y-chromosome-derived material Am J Med Genet A 135: 150-154, 2005.

9. Bianco B, Oliveira KC, Guedes AD, Barbosa CP, Lipay MV and Verreschi IT: OCT4 gonadal gene expression related to the presence of Y-chromosome sequences in Turner syndrome. Fertil Steril 94: 2347-2349, 2010.

10. Brant WO, Rajimwale A, Lovell MA, et al: Gonadoblastoma and Turner syndrome. J Urol 175: 1858-1860, 2006.

11. Bianco B, Lipay MV, Melaragno MI, et al: Detection of hidden Y mosaicism in Turner's syndrome: importance in the prevention of gonadoblastoma. J Pediatr Endocrinol Metab 19: 1113-1117, 2006.

12. Bianco B, Nunes Lipay MV, Guedes AD, Verreschi IT: Clinical implications of the detection of Y-chromosome mosaicism in Turner's syndrome: report of 3 cases. Fertil Steril 90: e17-e20, 2008.

13. Bianco B, Lipay M, Guedes A, Oliveira K and Verreschi IT: SRY gene increases the risk of developing gonadoblastoma and/or nontumoral gonadal lesions in Turner syndrome. Int J Gynecol Pathol 28: 197-202, 2009.

14. Verma RS and Babu A: Human Chromosomes: Manual of Basic Techniques. Pergamon Press, New York pp5-11, pp47-49, 1989.

15. Cortés-Gutiérrez EI, Cerda-Flores RM, Silva-Cudish JB, Dávila Rodríguez MI, Hernández-Herrera R and Leal-Garza CH: Evaluation of sex chromosome aneuploidies in women with Turner's syndrome by G-banding and FISH. A serial case study. J Reprod Med 48: 804-808, 2003.

16. Sallai A, Sólyom J, Dobos M, et al: Y-chromosome markers in Turner syndrome: screening of 130 patients. J Endocrinol Invest 33: 222-227, 2010

17. Modi D and Bhartiya D: Y chromosome mosaicism and occurrence of gonadoblastoma in cases of Turner syndrome and amenorrhoea. Reprod Biomed Online 15: 547-553, 2007.

18. Binder G, Koch A, Wajs E and Ranke MB: Nested polymerase chain reaction study of 53 cases with Turner's syndrome: is cytogenetically undetected $\mathrm{Y}$ mosaicism common? J Clin Endocrinol Metab 80: 3532-3536, 1995.

19. Coto E, Toral JF, Menéndez MJ, et al: PCR-based study of the presence of Y-chromosome in patients with Ullrich-Turner syndrome. Am J Med Genet 57: 393-396, 1995.

20. Ferández-García R, García-Doval S, Costoya S and Pásaro E: Analysis of sex chromosome aneuploidy in 41 patients with Turner syndrome: a study of 'hidden' mosaicism. Clin Genet 58 201-208, 2000.

21. Gicquel C, Gaston V, Cabrol S and Le Bouc Y: Assessment of Turner's syndrome by molecular analysis of the $\mathrm{X}$ chromosome in growth-retarded girls. J Clin Endocrinol Metab 83: 1472-1476, 1998.

22. Jacobs P, Dalton P, James R, Mosse K, Power M, Robinson D, et al: Turner syndrome: a cytogenetics and molecular study. Ann Hum Genet 61: 471-483, 1997.

23. López M, Canto P, Aguinaga M, et al: Frequency of Y chromosomal material in Mexican patients with Ullrich-Turner syndrome. Am J Med Genet 76: 120-124, 1998.
24. MedlejR,Lobaccaro JM,BertaP, et al: Screening for Y-derived sex determining gene (SRY) in 40 patients. J Clin Endocrinol Metab 75: 1289-1292, 1992.

25. Monroy N, López M, Cervantes A, et al: Microsatellite analysis in Turner syndrome: parental origin of $X$ chromosomes and possible mechanism of formation of abnormal chromosomes. Am J Med Genet 107: 181-189, 2002.

26. Osipova GR, Karmanov ME, Kozlova SI and Evgrafov OV: PCR detection of Y-specific sequences in patients with Ullrich-Turner syndrome: clinical implications and limitations. Am J Med Genet 76: 283-287, 1998

27. Vodicka R, Vrtel R, Scheinost O, et al: Refined quantitative fluorescent PCR of Y-chromosome DNA sequences mosaics in Turner's syndrome patients alternative to real-time PCR. J Biochem Biophys Methods 60: 151-162, 2004.

28. Alvarez-Nava F, Soto M, Sanchez MA, Fernández E and Lanes R Molecular analysis in Turner syndrome. J Pediatr 142: 336-340, 2003.

29. Kocova M, Siegel SF, Wenger SL, Lee PA, Nalesnik M and Trucco M: Detection of $\mathrm{Y}$ chromosome sequences in a $45, \mathrm{X} / 46, \mathrm{XXq}-$ patient by Southern blot analysis of PCR-amplified DNA and fluorescent in situ hybridization (FISH). Am J Med Genet 55: 483-488, 1995.

30. Larsen T, Gravholt CH, Tillebeck A, et al: Parental origin of the $\mathrm{X}$ chromosome, $\mathrm{X}$ chromosome mosaicism and screening for 'hidden' Ychromosome in 45, $\mathrm{X}$ Turner syndrome ascertained cytogenetically. Clin Genet 48: 6-11, 1995.

31. Mendes JR, Strufaldi MW, Delcelo R, et al: Y-chromosome identification by PCR and gonadal histopathology in Turner's syndrome without overt Y-mosaicism. Clin Endrocrinol (Oxf) 50: 19-26, 1999.

32. Nishi MY, Domenice S, Medeiros MA, Mendonca BB and Billerbeck AE: Detection of Y-specific sequences in 122 patients with Turner syndrome: nested PCR is not a reliable method. Am J Med Genet 107: 299-305, 2002.

33. Canto P, Kofman-Alfaro S, Jiménez AL, et al: Gonadoblastoma in Turner syndrome patients with nonmosaic 45, X karyotype and Y chromosome sequences. Cancer Genet Cytogenet 150: 70-72, 2004.

34. Page DC: Y chromosome sequences in Turner's syndrome and risk of gonadoblastoma or virilisation. Lancet 343: 240, 1994.

35. Semerci CN, Satiroglu-Tufan NL, Turan S, et al: Detection of $Y$ chromosomal material in patients with a 45, X karyotype by PCR method. Tohoku J Exp Med 211: 243-249, 2007.

36. Araujo C, Galera MF, Galera BB, Silvestre FG and Medeiros SF: Molecular identification of chromosome Y sequences in Brazilian patients with Turner syndrome. Gynecol Endocrinol 24: 713-717, 2008.

37. Kim HR, Shin JH, Jung WY and Lee JN: Identification of Y-chromosome by molecular analysis in patients with Turner syndrome. Korean J Lab Med 26: 131-136, 2006.

38. Bisat T, May K, Litwer S and Broecker B: Y chromosome mosaicism in the gonads, but not in the blood, of a girl with the Turner phenotype and virilized external genitalia. Clin Genet 44: $142-145,1993$.

39. Tejada MI, Mornet E, Tizzano E, Molina M, Baiget M and Boue A: Identification by molecular analysis of mosaic Turner's syndrome in an obligate carrier female for fragile $\mathrm{X}$ syndrome. J Med Genet 31: 76-78, 1994.

40. Bianco B, Lipay M, Guedes A, Oliveira K and Verreschi IT: SRY gene increases the risk of developing gonadoblastoma and/or nontumoral gonadal lesions in Turner syndrome. Int J Gynecol Pathol 28: 197-201, 2009.

41. Delbridge ML, Longepied G, Depetris D, et al: TSPY, the candidate gonadoblastoma gene on the human Y chromosome, has a widely expressed homologue on the X-implications for $\mathrm{Y}$ chromosome evolution. Chromosome Res 12: 345-356, 2004. 